Provost, P. J. \& Doetsch, R. N. (1960). J. gen. Microbiol. 22, 259-264

\title{
Biological Characteristics of an Obligate Anaerobic Amylolytic Coccus
}

\author{
By P. J. PROVOST aND R. N. DOETSCH \\ Department of Microbiology, University of Maryland, College Park, \\ Maryland, U.S.A.
}

SUMMARY: The morphological and physiological characteristics of an amylolytic rumen bacterium are described. The organism is an obligate anaerobic coccus which occurs in extremely long chains and exhibits marked pleomorphism. It is considered best placed in the genus Peptostreptococeus. The physiological characteristics and numbers in which the organism occurs suggest an important role in the rumen, especially under the conditions imposed by high-starch foeding.

At present the amylolytic group of authentic rumen bacteria includes several genera and species. Streptococcus bovis, to which considerable significance as a rumen starch-hydrolyser has been ascribed, is the best known of this group. Species of the genus Lactobacillus, as suggested by Oxford (1958), are also probably important members of this group Bacteroides amylophilus, an organism which cannot utilize glucose directly, is a rumen starch-hydrolyser described by Hamlin \& Hungate (1956). The closely related $B$. ruminicola (Bryant, Small, Bouma \& Chu, 1958) also is amylolytic and occurs in large numbers in the rumen. The above workers also described a new genus and species, Succinimonas amylolytica, which is starch-hydrolysing and found in large numbers in the rumen when diets supplemented with grain are fed. Starch-hydrolysing members of the genus Butyrivibrio have been found in large numbers in the rumen by Bryant \& Small (1956). Few spore-forming bacteria have been reported in the rumen; however, the anaerobic Clostridium lochheadii and the facultative anaerobic Bacillus licheniformis have been described respectively by Hungate (1957) and Appleby (1955). Both are amylolytic; but since they do not consistently occur in large numbers, their importance as rumen starch-hydrolysers is questionable. The rumen protozoa which ferment starch were considered by Oxford (1958). These organisms, as well as other as yet undescribed bacteria, undoubtedly play roles of importance in rumen starch hydrolysis. The work presented in this paper gives a description of the morphology and physiology of an amylolytic rumen bacterium, suggests an enlargement of the generally recognized characteristics of the genus Peptostreptococcus, and suggests that several rumen bacteria may be included in this genus.

\section{METHHODS}

An eight-year-old permanently fistulated Holstein cow served as the source of rumen samples. Its high-starch diet consisted of $17 \cdot 6 \mathrm{lb}$. flaked corn and $6 \mathrm{Ib}$. alfalfa pellets per day. Samples were taken after a 3 -week period on 
this diet. Dilutions of rumen liquor were made in medium $(99 \mathrm{ml}$.) contained in milk dilution bottles under $\mathrm{a} \mathrm{CO}_{2}$ atmosphere. The composition of the medium was (g./l.): $\mathrm{Na}_{2} \mathrm{HPO}_{4}, 5 \cdot 2 ; \mathrm{KH}_{2} \mathrm{PO}_{4}, 4 \cdot 6 ; \mathrm{NaCO}_{3}, 5 \cdot 0$; sodium thioglycollate, $1 \cdot 0$; resazurin, 0.001 .

All culture media were anaerobic, being made so by the addition of reducing agents (sodium thioglycollate, cysteine hydrochloride) and by the removal of oxygen from the gas phase above the medium by flushing with carbon dioxide or nitrogen. These techniques were basically the same as those described by Hungate (1950), Doetsch, Robinson \& Shaw (1952) and Bryant \& Burkey (1958). The principal media used were:

(1) Rumen fluid + glucose + cellobiose + starch agar (RGCSA) which was used for isolation purposes. Its composition was the same as the RGCA medium of Bryant \& Burkey (1953), except for the addition of $0 \cdot 1 \%(w / v)$ soluble starch.

(2) 'Reinforced clostridial medium' RCM (Hirsch \& Grinsted, 1954). As used this medium was modified to contain (g./l.): beef extract (Difco), 10.0; bacto-peptone (Difco), 10.0; yeast extract (BBL; Baltimore Biological Laboratory. Inc. Baltimore, Md., U.S.A. ) 3.0; $\mathrm{KH}_{2} \mathrm{PO}_{4}$ and $\mathrm{K}_{2} \mathrm{HPO}_{4}, \mathbf{3 . 0}$; resazurin, 0.001; agar, 20.0; glucose, 5.0; soluble starch, 1.0; $\mathrm{Na}_{2} \mathrm{CO}_{3}, 3.0$; cysteine hydrochloride, $0 \cdot 5$. This medium was used mainly for culture maintenance.

(3) Liquid thioglycollate medium (BBL). This commercially prepared medium contained no added carbohydrate or yeast extract and was used as a basal medium in many of the studies. When used unaltered and with a $\mathrm{CO}_{2}$ gas-phase, it had a $\mathrm{pH}$ value slightly higher than 6.0. With $0.3 \%(\mathrm{w} / \mathrm{v}) \mathrm{Na}_{2} \mathrm{CO}_{3}$ and $\mathrm{CO}_{2}$ gas phase the $\mathrm{pH}$ value was $c .7 \cdot 0$. Both modifications of the medium were used. Yeast extract, carbohydrates or agar were also added when required, depending upon the intended use of the medium.

Morphology was studied by using the Gram strain (Hucker's modification), Dyar cell-wall stain (Dyar, 1947) and various simple stains. Photographs were taken at a magnification of $\times 2275$; the light source was passed through a Wratten $B$ no. 58 (green) filter. The routine biochemical determinations were performed by conventional techniques as described in the Manual of Microbiological Methods (1957). Analysis of original and residual carbohydrate in culture media was performed by using the anthrone reagent (Morris, 1948). Fermentation acids were determined by a modification (acetone and hexane as eluting agents) of the column chromatographic technique described by Wiseman \& Irvin (1957).

\section{RESULTS}

The organism described herein was isolated on the RGCSA medium from a $1 / 10^{8}$ dilution of high-starch diet rumen liquor. On slopes of RCM, RGCSA or thioglycollate agar $\left(37^{\circ}\right)$, the organism developed in the butt of the tube; little or no growth occurred on the slope itself. Growth was very sparse at $24 \mathrm{hr}$. and only moderate at $48 \mathrm{hr}$. Early growth in the butt appeared as spiall rough discrete colonies which later fused. Spreading growth between 
the agar and the wall of the tube was characteristic. This was thought to indicate motility, but true motility was not demonstrable by other means. Surface colonies on RCM agar medium or thioglycollate agar were c. 0.5$1.0 \mathrm{~mm}$. in diameter, smooth, glistening, translucent, dull white, regularly marginated and slightly convex. In semi-solid agar media $(0 \cdot 3 \%, \mathrm{w} / \mathrm{v}$, agar), the colony form was the same as that described for the butts. In fluid media containing $0.05 \%(w / v)$ agar, the growth appeared as suspended, discrete, rough colonies which readily dispersed on shaking. In liquid media a loosely packed sediment occurred. No growth appeared in any of the test media under aerobic conditions.

The cellular morphology of the isolate was most striking; Pl. 1, figs. 1-5, show different phases of development. The organism is Gram-negative but heavily granulated in young cultures. Its morphology is that of cocci in long chains, although at some phases this is not apparent. The cocci show an unusual tendency to remain attached after division (Pl. 1, fig. 1), in fact, some chains consist of more than 100 elements.

The routine biochemical tests showed that the organism did not produce catalase, hydrogen sulphide, indole, or acetylmethylcarbinol. Nitrate was not reduced to nitrite. Gelatin was not liquefied. An acid curd which separated into very hard particles was formed in skim milk cultures supplemented with cysteine hydrochloride, yeast extract, $\mathrm{Na}_{2} \mathrm{CO}_{3}$ and carbon dioxide. The hard particles of curd were probably due to the entwinement of long chains of cocci. The final $\mathrm{pH}$ value in milk was $4 \cdot 6$. Crystal violet $(1 / 100,000)$ was inhibitory to growth. The organism was sensitive to penicillin (10 units/disk), aureomycin ( $30 \mu \mathrm{g} . /$ disk), and tetracycline ( $30 \mu \mathrm{g} . /$ disk) used in the form of BBL 'sensiDises'.

In RCM agar stab cultures good growth occurred at $37^{\circ}$ and $45^{\circ}$; slight growth was evident at $30^{\circ}$; no growth appeared at $20^{\circ}, 2^{\circ}$, or $55^{\circ}$. Viability in freshly inoculated thioglycollate broth cultures was maintained at $60^{\circ}$ for $10 \mathrm{~min}$., but not after the same period of heating at $70^{\circ}$ or more. This observation, along with the absence of visible spores, indicates asporogenesis.

A requirement of carbon dioxide for growth was shown by using thioglycollate broth. Under a nitrogen atmosphere no growth occurred in this medium with or without the addition of $0.8 \%(w / v)$ yeast extract. However, in the same medium, good growth occurred when carbon dioxide was substituted for nitrogen.

An interesting effect on the rate of growth and total crop was produced by yeast extract which was not necessary for growth in the liquid thioglycollate medium $(B B L)+1.0 \%(w / v)$ glucose. When yeast extract was not added to this medium growth occurred more quickly at pH 6.2 than at pH 6.9, but the total crop after 4 days of incubation was the same at each $\mathrm{pH}$ value (optical density at $640 \mathrm{~m} \mu, \mathrm{OD},=0 \cdot 12)$. With the addition of $0.3 \%(\mathrm{w} / \mathrm{v})$ yeast extract to the liquid thioglycollate medium (BBL) growth at $\mathrm{pH} \mathrm{6.2} \mathrm{was} \mathrm{greatly}$ enhanced (OD at $640 \mathrm{~m} \mu=0.6$ at 4 days) whereas at $\mathrm{pH} 6.9$ there was no increase. Yeast extract at $0.05 \%(w / v)$ did not enhance growth even at 
pH 6.2. In a medium consisting of acid-hydrolysed casein (Nutritional Biochemicals Corp., Cleveland 28, Ohio, U.S.A.) plus salt, sodium thioglyeollate and ghucose at pH 6.0, no growth occurred. However, with the further addition of $0.3 \%(w / v)$ yeast extract, good growth was evident. From these results it would appear that some material in yeast extract was more effective at the lower $\mathrm{pH}$ values.

The following carbohydrates $(1 \%, w / v$, sterilized with ethylene oxide) in thioglycollate broth at pH 7.0 were fermented: arabinose, xylose, glucose, fructose, mannose, galactose, mannitol, maltose, lactose, cellobiose, sucrose, trehalose, raffinose, dextrin, glycogen, soluble starch, pectin. The final value in the glucase medium was 4.8. Inositol, dulcitol, sorbitol, glycerol, xylan and lactate (as sodium lactate, $1 \% \mathrm{w} / \mathrm{v}$ ) were not attacked.

From glucose or starch, acetic, formic and lactic acids were the main end products. In a Trypticase + yeast extract medium with $1 \%(w / v)$ glucose, $0.6 \%(w / v) \mathrm{K}_{2} \mathrm{HPO}_{4}$ and $\mathrm{KH}_{2} \mathrm{PO}_{4}$ and with cysteine hydrochloride in place of sodium thioglycollate, $71 \%$ of the glucose was fermented and $92 \%$ of the carbon was accounted for in the recovery of the above acids by column chromatography. The ratio $(\mu \mathrm{M})$ of lactic:formic:acetic acid was about $5: 8: 2$; that is, from $39.4 \mu$ mole glucose fermented, $33 \mu$ mole formic acid, $20 \mu$ mole acetic acid and $48 \mu$ mole lactic acid were recovered. The same acid products in a similar ratio were recovered from soluble starch.

\section{DISCUSSION}

It is rather difficult to supply a satisfactory generic designation for the described organism on the basis of Bergey's Manual (Breed, Murray \& Smith, 7th edition, 1957). It has properties linking it with the family Lactobacillaceae: it is catalase negative, does not reduce nitrate, is dependent upon a carbohydrate source for growth, and forms appreciable quantities of lactic acid during fermentation of such substrates. Within this family, it is tempting to assign the organism to the genus Peptostreptococcus, since organisms of this genus are described as anaerobic cocci occurring in chains. The deseribed organism differs from all of the listed species of this genus in that it is Gramnegative rather than Gram-positive, albeit numerous Gram-positive granules are often seen to be distributed throughout the cytoplasm. Physiologically, similarities between it and some of the described species do exist. For example, Peptostreptococcus intermedius ferments several sugars producing a low $\mathrm{pH}$ value, some lactic acid and no gas. Of the anaerobic cocei described by Thomas \& Hare (1954), those of group VIa would appear closely related to the present organism; they too ferment carbohydrates with no gas production and oecur in chains.

Organism no. 27 of Moir \& Masson (1952), deseribed as 'large streptococci showing both loosely and tightly packed cells', has a morphology similar to the present isolate. In reference to organism no. 27 , it is interesting to note the further interpretation concerning the morphology of these streptococeal forms by Smiles \& Dobson (1956). They deseribe them as occurring in chains 
of two types: in one type the separated cocci are connected by filaments; in the other, long rods contain disk-like or partially flattened cocci. The organism described in the present paper shows both forms. Recently, Peptostreptococcus elsdenii n.sp. was described in detail by Gutierrez, Davis, Lindahl \& Warwick (1959). But for a similar morphology, this organism is quite different from the present isolate, especially as regards carbohydrates fermented and fermentation products.

Cultures of the described organism have been deposited in the National Collection of Industrial Bacteria, Teddington, Middlesex, and as ATCC 13627 in the American Type Culture Collection, Washington, D.C., U.S.A.

\section{REFERENCES}

Appleby, G. C. (1955). The isolation and classification of proteolytic bacteria from the rumen of the sheep. J. gen. Microbiol. 12, 526 .

Bergey's Manual of Determinative Bacteriology (1957). Ed. R. S. Breed, E. G. D. Murray \& N. R. Smith (7th ed.), Baltimore, Md.: Williams and Wilkins.

Bryant, M. P. \& Burkey, L. A. (1953). Cultural methods and some characteristics of some of the more numerous groups of bacteria in the bovine rumen. J. Dairy Sci. 36, 205.

Bryant, M. P. \& Small, N. (1956). The anaerobic monotrichous butyric acid-producing curved rod-shaped bacteria of the rumen. J. Bact. 72, 16.

Bryant, M. P., Small, N., Bouma, C. \& Chu, H. (1958). Bacterioides ruminicola n.sp. and Succinimonas amylolytica the new genus and species. J. Bact. 76, 15.

Doetsch, R. N., Robinson, R. Q. \& Shaw, J. C. (1952). Techniques employed in cultural investigations of the bacteriology of bovine rumen contents. J. Anim. Sci. 11, 536.

Dyar, M. J. (1947). A cell wall stain employing a cationic surface-active agent as a mordant. J. Bact. 53, 498.

Gutterrez, J., Davis, R. E., Lindakt, I. L. \& Warwick, E. J. (1959). Bacterial changes in the rumen during the onset of feed-lot bloat of cattle. Appl. Microbiol. 7, 16.

Hammton, L. J. \& Hungate, R. E. (1956). Culture and physiology of a starchdigesting bacterium (Bacteroides amylophilus, n.sp.) from the bovine rumen. J. Bact. 72, 548.

Hirsch, A. \& Grinsted, E. (1954). Methods for the growth and enumeration of anaerobic spore-formers from cheese, with observations on the effect of nisin. J. Dairy Res. 21, 101.

Hungate, R. E. (1950). The anaerobic mesophilic cellulolytic bacteria. Bact. Rev. 14, 1 .

Hungate, R. E. (1957). Microorganisms in the rumen of cattle fed a constant ration. Canad. J. Microbiol. 3, 289.

Manual of Microbiological Methods (1957). Society of American Bacteriologists. New York, N.Y.: McGraw-Hill.

Moir, R. J. \& Masson, M. J. (1952). An illustrated scheme for the microscopic identification of the rumen microorganisms of sheep. J. Path. Bact. 64, 348.

Morris, D. L. (1948). Quantitative determination of carbohydrate with Dreywood's anthrone reagent. Science, 107, 254.

Oxford, A. E. (1958). The rumen ciliate protozoa: their chemical composition, metabolism, requirements for maintenance and culture, and physiological significance for the host. Exp. Parasit. 4, 569. 
Smrues, J. \& Donson, M. J. (1956). Direct ultra-violet and ultra-violet negative phase-contrast micrography of bacteria from the stomachs of the sheep. $J$. roy. micr. Soc. 75, 244.

Tronas, C. G. A. \& Hare, R. (1954). The classification of anaerobic cocci and their isolation in normal human beings and pathological processes. J. clin. Path. 7, 300.

Wrseman, H. G. \& Invin, H. M. (1957). Determination of organic acids in silage. Agric. Food Chem. 5, 213.

\section{EXPLANATION OF PLATE}

Fig. 1. Coccoid forms in $15 \mathrm{hr}$. thioglycollate broth culture. Gram-negative, but with many Gram-positive granules. Medium originally pH 6.2. Gram stain. $(\times 2275$.

Fig. 2. 'Cigar-like' forms in $62 \mathrm{hr}$. thioglycollate broth culture. Regularly Gram-negative. Gram stain. ( $\times$ 2275.)

Fig. 3. Heavily septate filaments (tightly packed cocci) in 8-day thioglycollate broth culture. Gram-stain. $(\times \mathbf{2 2 7 5}$. $)$

Fig. 4. Dyar cell-wall stain of an $82 \mathrm{hr}$. thioglycollate broth culture showing cross-striations; indication of tightly packed cocci. ( $\times 2275$.)

Fig. 5. Crystal violet stain of $1 / 10$ dilution of normal diet rumen fluid showing an organism similar in morphology to the described isolate. $(\times 2275$.

(Received 7 August 1959) 
Journal of General Microbiology, Vol. 22, No. 1
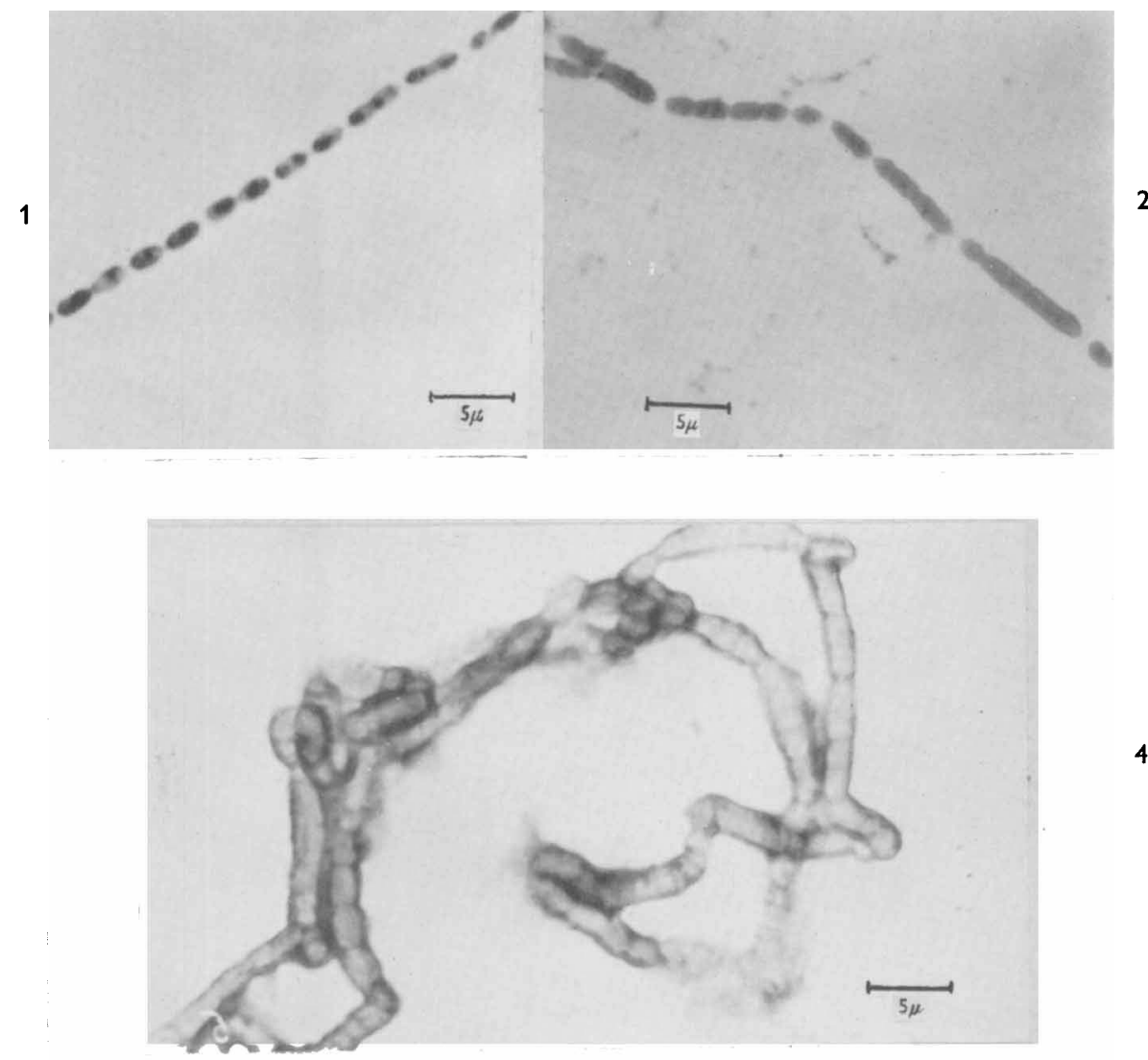

3

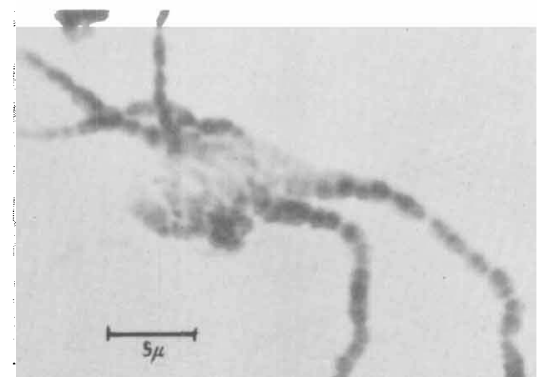

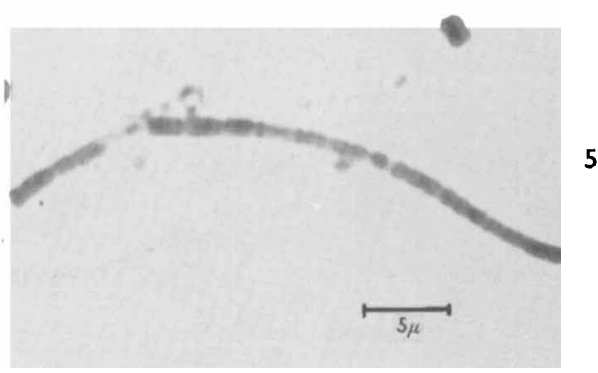

P. J. Provost \& R. N. Doetsch-An obligate anakrobic amyiolytic coccus

(Facing p. 264) 